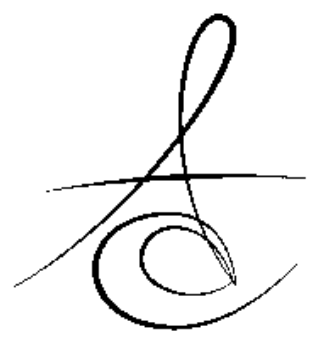

\title{
KERATİNİZE MUKOZANIN İMPLANTLARIN UZUN DÖNEM BAŞARISINDAKİ ÖNEMİ VE PALATÍNAL ROTASYONEL SAPLI FLEP UYGULAMASI: OLGU SUNUMU
}

\section{THE IMPORTANCE OF KERATINIZED MUCOSA IN LONG TERM MAINTENANCE OF DENTAL IMPLANTS AND PALATINAL ROTATIONAL PEDICULATED FLAP APPLICATION: CASE REPORT}

Yrd. Doç. Dr. Serhat KöSEOĞLU* Yrd. Doç. Dr. Mehmet SAĞLAM* Arş. Gör. Dt Seyfi KELEBEK ${ }^{* *}$

Makale Kodu/Article code: 1815

Makale Gönderilme tarihi: 09.09 .2014

Kabul Tarihi; 24.11 .2014

\section{ÖZET}

Dişeti sağlığını korunması ve periodontal hastalıkların ilerlemesinin önlenmesi adına belirli miktarda keratinize dişetinin gerekli olduğu düşünülmektedir. Restorasyon sınırlarının subgingival alana uzandığı dişlerde keratinize mukoza bandının ince olması dişeti iltihabı gelişme riskinin yüksek olması ile ilişkilidir. Ayrıca dental implantların uzun dönem başarısı kaçınılmaz bir şekilde; implant çevresi dokularda enfeksiyon gelişiminin engellenmesine ve/veya travmaya bağlı implant kayıplarının önüne geçilmesine bağlıdır. Bu olgu sunumunda dental implant yerleştirilmesi sonrası yetersiz keratinize mukoza bandı varlığı saptanan hastanın Palatinal Rotasyonel Saplı Flep (PRSF) tekniği ile tedavisi açıklanmıştır. Posterior maksilla bölgesine yerleştirilen iki implantın iyileşme dönemlerinde bukkal yüzeylerindeki alveol mukozada hareketlilik gözlenmiştir. Dişeti şekillendiricilerin koyulmasının ardından implant çevresindeki hareketli yumuşak doku PRSF tekniği ile düzeltilmiştir. Üç hafta sonunda implantların bukkal boyun bölgelerinde yaklaşık $3 \mathrm{~mm}$ keratinize mukoza elde edilmiştir. Sonuç olarak uzun dönem implant stabilitesi ve implant çevresi dokuların sağlığının korunması keratinize mukoza miktarı ile direk ilişkilidir. Tüm cerrahi işlemler implant uygulaması veya protetik yükleme gerçekleştirilmeden önce yapılmalıdır.

Anahtar kelimeler: Keratinize mukoza, dental implant, dişeti sağlığı

\section{ABSTRACT}

The presence of adequate zone of keratinized gingiva is thought to be necessary for the maintenance of gingival health and prevention of periodontal disease progression. In teeth with subgingival restorations, narrow zone of keratinized mucosa is associated with higher chance of gingival inflammation. Also, prevention of periimplant tissue infection and/or traumatic loss are inevitable for the long term success of dental implants. This case report describes the rehabilitation of the inadequate keratinized mucosa band determined after dental implants placement, by using Palatinal Rotational Pediculated Flep technique (PRPF). Mobile alveolar mucosa at the buccal side of two implants which were placed at posterior maxilla was observed in the healing period. Mobile mucosa that surrounds periimplant area was managed with PRPF technique after placement of gingiva formers. The keratinized mucosa has been obtained approximately $3 \mathrm{~mm}$ at buccal cervical region of implants after three weeks. In conclusion, the long term stability and maintenance of dental implants are directly related to amount of keratinized mucosa at periimplant area. All surgical interventions would rather be carried out before the implant placement or the prosthetic loading.

Key words: Keratinized mucosa, dental implant, gingival health

\footnotetext{
* İzmir Katip Çelebi Üniversitesi Diş Hekimliği Fakültesi Periodontoloji AD

** İzmir Katip Çelebi Üniversitesi Diş Hekimliği Fakültesi Ağız, Diş ve Çene Cerrahisi AD
} 


\section{GİRİş}

Yapışık dişeti, hareketli alveol mukozadan mukogingival hatla ayrılan, altındaki alveol kemiğine periost yoluyla sıkıca tutunan, dişin mine sement sınırına doğru serbest dişeti ile devam eden, sıkı ve dirençli bir yapıdır. Mukogingival birleşimin yeri ömür boyu sabit kaldığından yapışık dişetinin genişliği koronal bölümünün pozisyonundaki modifikasyonlara bağı olarak değişmektedir.1,2 Doğal dişlerde yeterli miktarda yapışık dişetinin bulunması, çiğnemenin fiziksel travmalarına ve dişetine direkt temas eden beslenme ürünlerinin termal ve kimyasal hasarlarına karşı direnç gösteren etkili bir bariyer olarak rol

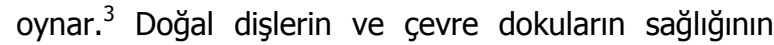
devamlılı̆ı için olması gereken keratinize mukoza miktarının en az $\geq 1 \mathrm{~mm}$ 'si yapışık dişeti olmak kaydıyla genellikle $\geq 2 \mathrm{~mm}$ olarak bildirilmektedir. ${ }^{4}$ Doğal dişlerin ve implant çevresindeki destek dokuların devamlıı̆̆ının, yapışık dişeti olmadığı durumlarda tehlikede olduğu söylense de bu konuyla ilgili cerrahi yaklaşımlar literatürde tartışmalıdır. ${ }^{5}$

Dental implantların kullanılmasıyla beraber kemik içi implantların çevresinde yapışık mukozanın gerekliliği tartışılmaya başlanmıştır. Literatürde ağız hijyen durumuna bakmadan yapılan değerlendirmelerde, implant üstü sabit ve hareketli restorasyonların çevresinde keratinize dişeti varlığının doğal diş yapılarından daha fazla öneme sahip olduğu bildirilmektedir. ${ }^{5,6}$ İmplantlarda sement ve periodontal ligamentin olmaması, daha az fibroblast ve vasküler yapı olması, bağdokusu oryantasyonunun implant yüzeyine paralel olması gibi doğal dişlere göre bir takım farklılıklar vardır. Mikrobiyal kolonizasyon veya plak birikimi söz konusu olduğunda enflamasyon gelişimi ve kemik kaybı miktarının implantlarda doğal dişlere göre daha fazla olduğu söylenmektedir. ${ }^{6}$ Restorasyonlar subgingival olarak yerleştirildiğinde daha yüksek oranda enflamasyon, ataşman kaybı ve dişeti çekilmesi görülmektedir. ${ }^{7}$ Bu şekilde dizayn edilmiş restorasyonlarda optimal plak kontrolü sağlanamadığından minimal yapışık dişeti olan bölgelerde subgingival restorasyonlar ile dişeti enflamasyonu arasında anlamlı bir ilişki bulunmuştur. ${ }^{8}$ Özellikle optimum ağız hijyeni sağlanamayan hastalarda yetersiz miktarda yapışık dişeti varlığında restore edilmiş dişlerin ve/veya dental implantların periodontal destek dokularının uzun dönem devamlılı̆ı olumsuz etkilenmektedir. ${ }^{5,9}$

Dental implant cerrahisinden önce implant bölgesinde kalın bir bant şeklinde ( $\geq 2 \mathrm{~mm}$ ) veya ince bir çizgi şeklinde $(2 \mathrm{~mm}<)$ keratinize mukoza olabildiği gibi keratinize mukoza hiç mevcut olmayabilir. Bazı durumlarda da implant yapıldıktan sonra keratinize mukoza tamamen ortadan kalkabilir. Böyle durumlarda yapışık dişetinin sağladığı avantajları elde etmek için mukogingival cerrahi teknikler uygulanmaktadır. ${ }^{10}$ Mukogingival cerrahinin önemli hedeflerinden biri de dişlerin ve implantların çevresinde yeterli miktarda yapışık dişeti oluşturmak veya var olan genişliği arttırmaktır. Bu amaçla serbest dişeti greftleri, bağ dokusu greftleri, saplı flepler ve rotasyonel palatinal flep teknikleri uygulanmaktadır. Bu yöntemlerden biri olan palatinal rotasyonel saplı flep (PRSF) tekniği, Nemcovsky ve arkadaşları tarafından ilk olarak immediat implant cerrahisinde uygulanmıştır. ${ }^{11,12}$ Söz konusu yöntemle palatinal bölgede tam ya da yarım kalınlıklı flep kaldırılarak implantların çevresindeki yumuşak dokuların primer kapanması, diş çekimini takiben yapılan implantların çevresindeki kemik defektlerinin iyileşmesinin sağlanması ve rezidüel alveol kretin korunması amaçlanmıştır. Nemcovsky ve arkadaşları $^{11,12}$ bu teknikle aynı zamanda implant çevresinde restorasyonların uzun dönem başarısını arttıran keratinize mukoza da elde etmişlerdir. Bu olgu sunumunda üst çene sağ posterior bölgeye yerleştirilen iki adet implanta yapılacak restorasyonun uzun dönem başarısı için implantın bukkal yüzeyinde hiç mevcut olmayan keratinize mukozayı palatinalden kaldırılan flebin bukkale döndürülmesi suretiyle elde etmek amaçlanmıştır. Bu amaçla yapılan rotasyonel palatinal flep cerrahisinin klinik sonuçları sunulmuştur.

\section{OLGU}

Herhangi bir sistemik rahatsızlığı bulunmayan 46 yaşındaki bayan hasta diş eksikliği şikayeti ile kliniğimize başvurmuştur. Yapılan klinik ve radyolojik muayenenin ardından üst çene sağ posterior bölgeye iki adet implant yerleştirilerek diş eksikliğinin giderilmesi planlanmıştır. Birinci cerrahi aşama başarıyla gerçekleştirildikten sonra implantların osseointegrasyon süreci için 4 ay beklenmiştir. İkinci cerrahi aşama ile dişeti şekillendiriciler yerleştirilerek implantlar ağız ortamına açılmıştır (Resim 1A). Yapılan klinik 
muayenede molar bölgesine yerleştirilen implantta yapışık dişeti bulunmadığı anlaşılmıştır (Resim 1B). Söz konusu implantın tedavisi için palatinal bölgeden saplı rotasyonel flep uygulamasına karar verilerek implantın bukkalinde yatak hazırlanmıştır (Resim 2A). Palatinal flebin sınırları ilgili implantın mezialinden başlayarak alveol krete paralel olarak ilerletilmiştir ( 30mm uzunluk, $6 \mathrm{~mm}$ genişlik ve $2 \mathrm{~mm}$ kalınlık). Flep yarım kalınlık kaldırılarak bukkal bölgedeki hazırlanan yatağa 4-0 ipek sütur ile sabitlenmiştir (Resim 2B-D). Palatinal bölgedeki verici saha periodontal patla kapatılarak sekonder iyileşmeye bırakılmıştır. Operasyondan bir hafta sonra yapılan klinik muayenede implantın bukkal bölgesinde yaklaşık $3 \mathrm{~mm}$ yapışık dişeti oluştuğu ve palatinaldeki verici sahanın iyileştiği gözlenmiştir (Resim 3A). Hastanın protetik tedavisi tamamlandıktan altı ay sonra yeterli yapışık dişetinin varlığı tespit edilmiştir (Resim 3B).
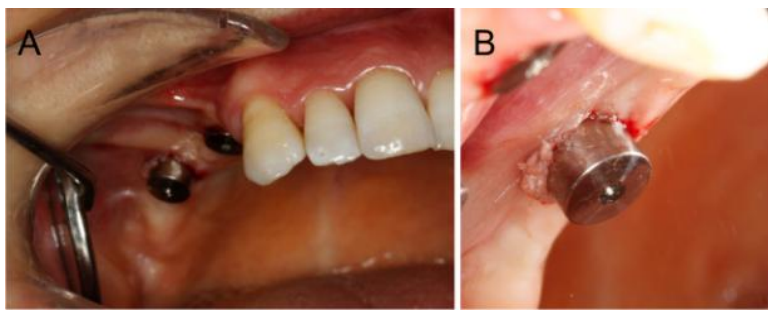

Resim 1. Operasyondan önce klinik görünüm; A- İmplant yapıldıktan 4 ay sonra sağ üst posterior bölgeye dişeti şekillendiricileri uygulanması B- Yapılan klinik muayenede implantın bukkalinde keratinize dişeti olmadığı saptanmıştır.

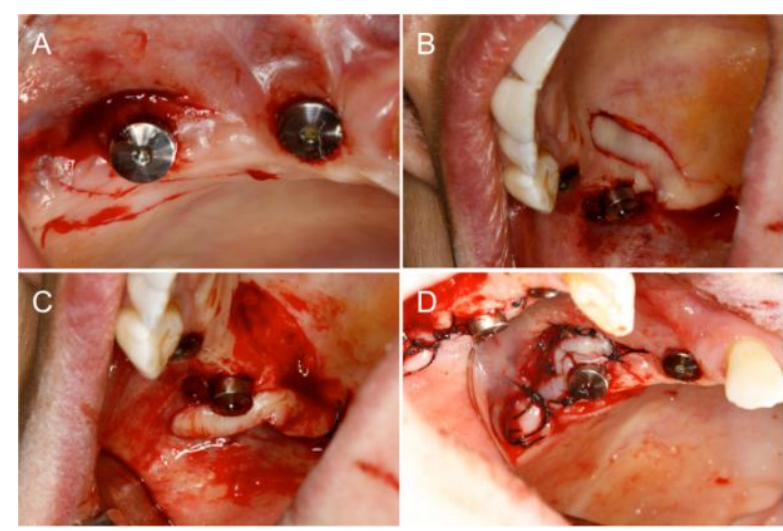

Resim 2. Cerrahi protokol; A- İmplantın bukkal bölgesinde yatak hazırlanması, B- Posterior palatal bölgede implantın distalinden mezialine kadar uzanan saplı flep sınırları, CFlebin yarım kalınlıklı kaldırıması, D- Daha önce hazırlanan yatağa yerleştirilen flebin sütüre edilmesi.
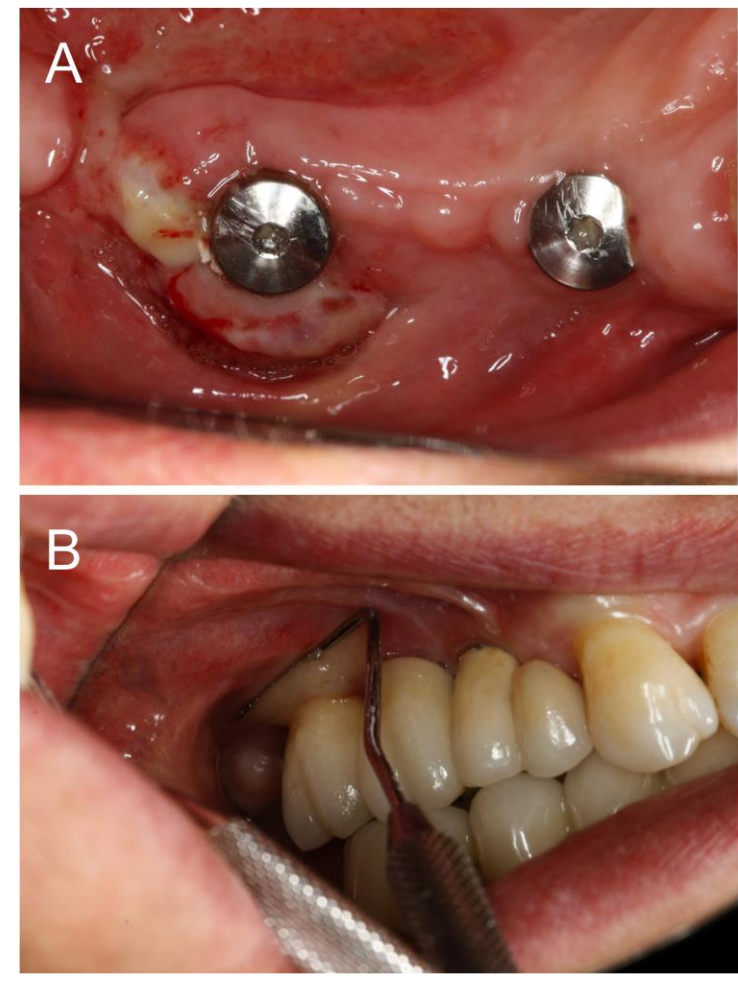

Resim 3. Operasyon sonrası 3. hafta klinik görünüm; A- Verici sahanın iyileşmesi, B- Bukkal yüzeyde yaklaşık $3 \mathrm{~mm}$ yapışık dişeti oluşmuştur.

\section{TARTIŞMA}

$\mathrm{Bu}$ olgu sunumunda, üst çenesinde posterior bölgede diş eksikliği olan hastada implant cerrahisinden sonra mevcut implantın bukkal boyun bölgesinde eksik olan keratinize mukozanın rotasyonel palatinal saplı flep ile tedavisi amaçlanmış, altı aylık klinik sonuçları sunulmuştur. Literatürde keratinize mukoza varlığı ile implantın uzun dönem başarısı arasındaki ilişkiyi inceleyen çalışmalara bakıldığında ortak bir sonuca varılamamıştır. ${ }^{5}$ Chung ve arkadaşları ${ }^{5}$ yaptıkları çalışmada keratinize mukoza varlığını savunanların pürüzlü implantları kullandıklarını; keratinize mukozanın önemine şüpheli yaklaşanların ise parlak yüzeyli implantları kullandıklarını bildirmişlerdir. Önceki çalışmalarda ${ }^{13,14}$ ayrı ayrı incelenen iki farklı implant yüzeyinde var olan keratinize mukoza miktarları değerlendirilirken Chung ve arkadaşları çalışmalarında iki faklı implant yüzeyinde var olan keratinize mukoza miktarlarını birlikte değerlendirip elde ettikleri verileri sunmuşlardır. Alveol kemik kaybı ile keratinize mukoza miktarı veya implant yüzey tipleri arasında anlamlı ilişki

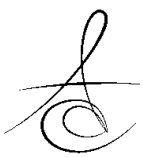


bulamamışlardır. Ancak pürüzlü yüzeyli implantların başarısında keratinize mukozanın önemli olabileceğini, keratinize mukozanın plak birikimini engellenmesinde ve gingival enflamasyonun azaltılmasında avantajlı olabileceğini bildirmişlerdir. Ayrıca çalışmanın sonuçlarında implant üstü sabit ve hareketli protezlerin implant bölgelerindeki keratinize mukozayla ilişkisine de bakılmıştır. Keratinize mukoza miktarı ile sabit veya hareketli protez ile restore edilmiş implantların klinik parametreleri arasında korelasyon bulamamışlardır. ${ }^{5}$ Bouri ve arkadaşları ${ }^{4}$ ince keratinize mukoza bandı (< $2 \mathrm{~mm}$ ) olan implantların, kalın keratinize mukoza bandı ( $\geq 2 \mathrm{~mm}$ ) olan implantlara göre anlamlı olarak daha fazla plak birikimi ve enflamasyon belirtilerine sahip olduklarını göstermişlerdir. İnce keratinize mukoza bandı olan implantların sondalamada kanamaya daha eğilimliyken; kalın keratinize mukoza bandı olan implantların enflamasyonun apikale migrasyonunda daha dirençli olduğu bulunmuştur. Bouri ve arkadaşları ${ }^{4}$ sonuçlarında, geniş keratinize mukoza bandının çiğneme kuvvetlerine ve ağız bakımı sırasında oluşan sürtünme kuvvetlerine karşı daha fazla direnç göstereceğini bildirmiştir.

$\mathrm{Bu}$ vakada palatinal flep implantın distalinden döndürülerek meziale doğru hazırlanan yatağa yerleştirilmiştir. Serbest dişeti greftinin kanlanması PRSF kadar iyi değildir. ${ }^{15,16}$ Bağ dokusu grefti de aynı zamanda serbest grefttir ve keratinize mukoza oluşturmada iyileşme sonrası büzülme göstermektedir. ${ }^{17}$ Kaydırma flep operasyonlarında başlangıçta yetersiz olan vestibül sulkusun derinliği daha da azalabileceğinden verici bölgedeki dişetinde potansiyel çekilme riskine karşı palatinal flep tekniği tercih edilmiştir. $^{18}$

Nemcovsky ve arkadaşları ${ }^{11,12}$ yaptıkları çalışmada PRSF kullanarak immediat implantasyon sonrası yara bölgesinin primer kapanmasına ve yerleştirilen implantın çevresindeki kemik defektine membranlı veya membransız uygulanan allojenik kemik greftlerinin iyileşmesine bakmışlardır. Flep perforasyonu riskine karşı ve kanlanmayı yeterince sağlamak için palatinalde minumum $4 \mathrm{~mm}$ kalınlıkta keratinize dişeti olan hastaları seçmişlerdir. Serbest dişeti greftini; kronale veya laterale kaydırılan flep tekniklerini tercih etmemişlerdir. ${ }^{12}$ Çalışmanın sonuçlarında immediat implantasyon sonrası alveol kemik yüksekliğinin daha iyi korunduğu, papil formunun daha iyi sağlanmasıyla estetik beklentilerin gerçekleştiği ve implant boyun çevresinde keratinize mukoza oluşturularak daha iyi fonksiyon ve temizlenebilirlik sağlandığı bildirilmiştir. ${ }^{12}$ Literatüre bakıldığında implantların uzun dönem başarısında, enflamasyona karşı bariyer oluşturmada, hastanın ağız hijyenini sağlamasında keratinize mukoza varlığı ciddi bir öneme sahiptir. İmplantlarda keratinize dokunun gerekliliği tartışmalıdır ve kesin bir yargı bulunmamaktadır. Bu önemin istatiksel olarak çalışmalara yansıması için uzun süreli, çok merkezli, hasta sayısı fazla olan, kontrollü klinik çalışmalara intiyaç vardır. İmplant cerrahisi öncesinde veya sonrasında yetersiz keratinize mukoza miktarında artış mukogingival cerrahi yöntemlerini etkin bir şekilde uygulanması ile sağlanabilir. Bu sayede implantların uzun dönem başarısı için daha az riskli bir ortam oluşturulacaktır. İmplant yerleştirmesinden/ planlamasından önce sadece sert dokuları değil yumuşak dokuların da implantların uzun dönem başarısı için dikkatlice değerlendirilmesi gerekmektedir.

\section{KAYNAKLAR}

1. Newman MG, Takei HH, Caranza FA. Carranza's Clinical Periodontology. 10 ed. New York; WB Saunders Co: 2006. p. 47.

2. Kennedy JE, Bird WC, Palcanıs GK, Dorfman HS: A longitudinal evaluation of varying widths of attached gingiva. J Clin Periodontol.1985;12:66775.

3. Camargo PM, Melnick PR, Kenney EB. The use of free gingival grafts for a esthetic purposes. Periodontol 2000. 2001; 27: 72-96.

4. Bouri A, Bissada N, Al-Zahrani M, Faddoul F, Nouneh I. Width of keratinized gingiva and the health status of the supporting tissues around dental implants. Int J Oral Maxillofac Implants. 2008;23:323-6.

5. Chung DM, Oh TJ, Shotwell JL, Misch CE, Wang HL. Significance of keratinized mucosa in maintenance of dental implants with different surfaces. J Periodontol .2006;77:1410-20.

6. Padbury Jr A, Eber $\mathrm{R}$, Wang $\mathrm{H}-\mathrm{L}$. Interactions between the gingiva and the margin of restorations. J Clin Periodontol.2003; 30: 379-85.

7. Chavrier CA, Couble ML. Ultrastructural immuno histochemical study of interstitial components of the healthyhuman keratinized mucosa surrounding 
implants. Int J Oral Maxillofac Implants. 1999; 14:108-12.

8. Stetler KJ, Bissada NF. Significance of the width of keratinized gingiva on the periodontal status of teeth with submarginal restorations. J Periodontol. 1987; 58: 696-700.

9. Çakır M, Bozkaya S, Tümer K, Ergün G, Yılmaz D. Rezorbe atrofik mandibulada implant yumuşak doku arayüzünün düzenlenmesinde vestibüloplasti tekniğinin kullanılması. Atatürk Üniv DişHek Fak Derg. 2013;21:356-61.

10. Palacci $P$, Nowzari $H$. Soft tissue enhancement around dental implants. Periodontol 2000. 2008;47:113-32.

11. Nemcovsky CE, Artzi Z, Moses O. Rotated palatal flap in immediate implant procedures. Clinical evaluation of 26 consecutive cases. Clin Oral Implants Res. 2000; 11: 83-90.

12. Nemcovsky CE, Artzi $Z$, Moses $O$. Rotated split palatal flap for soft tissue primary coverage over extraction sites with immediate implant placement. Description of the surgical procedure and clinical results. J Periodontol.1999; 70: 926-34.

13. Kirsch A, Ackermann KL. The IMZ osteointegrated implant system. Dent Clin North Am 1989;33: 73391.

14. Wennstro"m JL, Bengazi F, Lekholm U. The influence of the masticatory mucosa on the periimplant soft tissue condition. Clin Oral Implants Res 1994;5:1-8

15. Nobuto T, Imai $\quad H, \quad$ Yamaoka A. Microvascularization of the free gingival autograft. J Periodontol.1988; 59:639-46.

16. Brasher WJ, Rees TD, Boyce WA. Complications of free grafts of masticatory mucosa. J Periodontol.1975;46:133-8.

17. Cordioli G, Mortarino C, Chierico A, Grusovin MG, Majzoub Z. Comparison of 2 techniques of subepithelial connective tissue graft in thetreatment of gingival recessions. J Periodontol.. 2001;72, No:1470-6.

18. Santana RB, Furtado MB, Mattos MC, Fonseca $E M$, Dibart $S$. Clinical evaluation of single-stage advanced versus rotated flaps in the treatment of gingival recessions. J Periodontol. 2010;81:485-92.

\section{Yazışma Adresi}

Yrd. Doç. Dr. Serhat KÖSEOĞLU

İzmir Katip Çelebi Üniversitesi,

Aydınlık Evler Mahallesi,

Cemil Meriç Caddesi,

6780 Sokak. No:48,

35640-Çiğli/İZMİR

Tel: 02323252371

e-mail: serhatkoseoglu@gmail.com 